\title{
Integrating Mental Health Care for People Living with HIV
}

\section{Adriana Carvalhal*}

Department of Psychiatry, University of Toronto, Canada

\section{Introduction}

While mortality from AIDS has been largely controlled in many countries through the use of antiretroviral therapy (ART), many physical and neuropsychiatric complications remain the focus of serious health concerns [1]. For over a decade, research has shown that rates of mental health problems may be as high as $50 \%$ in people living with HIV (PHAs) [2]. Despite the high prevalence of mental illness, psychiatric disorders are commonly under-diagnosed and undertreated in this population [3].

The relationship between HIV and psychiatric disorders is complex. HIV can stress the already compromised coping skills of the mentally ill; conversely, mental illness can affect risk behaviours and increase the likelihood of someone contracting HIV. HIV-positive individuals must also face the prospect of social stigma, long-term physical discomfort, illness and death [4]. Antiretroviral therapy has transformed the reality of HIV by reducing morbidity and mortality, but optimal results require close follow-up with providers and strict adherence to medication [3]. Psychiatric comorbidities are associated with poorer adherence to ART, leading to virologic and immunologic failure; co-morbidities may also impede the use of medical services and increase the physical and emotional demands on formal and informal caregivers [5].

The care of PHAs is increasingly complex and demands an innovative model of care delivery involving multidisciplinary teams and inter-professional collaboration [6]. In particular, patients with triple diagnoses of HIV, substance use and psychiatric disorders pose a challenge to treatment, especially in initiation and adherence to antiretroviral treatment due to a plethora of complex biological and psychosocial consequences [7]. In order to illustrate the complex world of co-morbidities in HIV patients, we will present the story of "Susan" (a pseudonym). We will then describe an integrated mental health care for people living with HIV at St. Michael's Hospital in Toronto, Canada. Integrated models of care are patient-centered, and they not only involve the psychiatrist as a consult with co-location of psychiatric and medical services, but also involve a shared responsibility for the care of all patients within a service [8]. Integrated models of care involving mental health and other health care professionals have demonstrated improved medical and mental health outcomes in medical complex patients including HIV-infected patients [8-11].

\section{Susan's story}

Susan was 35 year-old female patient when she arrived at the Emergency Department (ED) of St. Michael's Hospital. Originally from a small town in northern Ontario, she was staying with friends in Toronto. She sought help at the ED due to chronic abdominal pain. When Susan was told by the triage nurse about the wait time to see the doctor, she became quite upset and began to scream. Security was called, while Susan began to demand painkillers and refused to answer questions. After an extensive workup, the medical team discovered that Susan was experiencing liver failure. At this point, she began to cry and disclosed that she was HIV-positive and also had hepatitis C. She had known about these conditions for years, but had not sought treatment to avoid public knowledge of her conditions in her hometown. At St. Michael's Hospital, Susan was also diagnosed with disseminated mycobacterium avium complex infection, and with HIV-associated lymphoma and end-stage liver disease. Susan revealed that she had a long history of mental health problems, with previous diagnoses of Bipolar Disorder and Substance-related Disorder. She also revealed a history of childhood sexual abuse, injection drug use and prostitution. It became clear that Susan did not want to return to her small town. She had two small children under the care of her parents, and she was afraid to lose access to the children. Her family was not aware of her HIV-related problems.

This case can clearly illustrate the complexity of many HIV-infected patients. We would like to reflect on what could happen with Susan's case in many centers across Canada.

- Should her depressive symptoms increase during the hospital admission a Consultation-Liaison (CL) psychiatrist would be asked to provide consultation to the HIV team. However, the psychiatrist would likely have little experience with HIV.

- There could be a recommendation to start a specific medication. However, the CL psychiatrist would not be fully familiar with the antiretroviral therapy that Susan would soon be starting and potential drug-drug interactions.

- The HIV team would know that Susan would need psychiatric follow up upon discharge from the hospital. The discharger planner for the HIV inpatient unit would contact the psychiatry outpatient clinic and learn that wait times would be several months and in many center, only consultation would be provided and no guarantee of follow-ups.

- The HIV team probably would have serious concerns about how well Susan would adhere to ART. The team would also be worried about Susan's lack of social support and inability to navigate in a complex health care system.

\section{An integrated model of psychiatric care}

Over the last 10 years, the literature in the field of CL Psychiatry has been describing different models of mental health care delivery that were developed to meet the needs of medically ill patients. These models range from a more traditional approach in which psychiatric consultation is provided upon request (also known as "reactive") and the psychiatrist has no primary patient responsibility to more integrative models, in which there is a 'proactive' case finding and more systemic mental health involvement. The integrative model of care in

${ }^{*}$ Corresponding author: Adriana Carvalhal, Mental Health Service, St Michael's Hospital, 30 Bond Street, 17-042Toronto, Ontario M5B 1W8, Canada, Tel: 416864-6060, E-mail: adriana.carvalhal@utoronto.ca

Received August 22, 2014; Accepted September 22, 2015; Published September 29, 2015

Citation: Carvalhal A (2015) Integrating Mental Health Care for People Living with HIV. Health Care Current Reviews 3: 139. doi: 10.4172/2375-4273.1000139

Copyright: (c) 2015 Carvalhal A. This is an open-access article distributed under the terms of the Creative Commons Attribution License, which permits unrestricted use, distribution, and reproduction in any medium, provided the original author and source are credited. 
CL includes also an important educational component that is executed formally and informally to build capacity within the medical team to better recognize and manage psychiatric disorders over time [8-12].

In our recent article "Journeying with HIV Patients Across the Healthcare Spectrum - An Examination of a Seamless Model of HIV Psychiatry of a Large Urban General Hospital" [13], we describe a model used in a large urban-setting tertiary hospital in Toronto, Canada, that offers an HIV Psychiatry service. St Michael's Hospital is an academic and research hospital with 467 acute inpatient beds and strong partnerships with more than 65 community organizations to provide care and ensure health equity to the marginalized and disadvantaged communities situated in the inner city of downtown Toronto. This integrative model of psychiatric care was implemented in this innercity hospital to provide psychiatric care for some of the hardest to reach HIV patients (Figure 1). This model also was developed to improve access to psychiatric care and includes a terciary team based in the hospital, two family practices and three key community partners. After 2 years of implementation, the program has been increasing the number of referrals and early recognition of psychiatric disorders in the HIV population served by the hospital reducing also waiting time and increasing the number of patients receiving on going care. The model also has been providing a more effective working relationship with and strong support from all stakeholders to provide better care for complex patients. Ultimately, the model has been increasing engagement in the HIV care cascade and improved adhrence to antiretroviral treatment.

\section{Let's go back to Susan}

What happened with 'Susan' in the integrated model described in the recent article of General Hospital Psychiatry [13]? After Susan arrives at St. Michael's Hospital, (the following day), the team met and a psychiatrist (integrated to the HIV team) was assigned to assess the patient since she had a long history of Bipolar Disorder. The HIV team considered a trial with opiates to treat abdominal pain but they had concerns about her previous history of Substance-related Disorder. The nurse that admitted Susan the day before shared with the team that patient could sometimes be verbally abusive to staff. The team requested some guidance from Psychiatry on how to manage any anger outbursts and the best way to support the patient.

Susan was born in Toronto and moved to north of Ontario when she was 8 years old. She described her father as being verbally, physically, and sexually abusive. She got involved in prostitution from a young age and was further placed in foster care. She was adopted at age of 13 and ran away from home when she turned 18. She met the father of her children in a bar where she used to exchange sex for drugs. They moved in together and, at that point, he became emotionally manipulative and physically violent. Child protection became involved with her family during an episode of violence. Her parents had been supportive but, as described by Susan, they do it "the way they can, but they don't understand my life".

The team discussed Susan's pharmacological treatment in order to develop a safe, effective plan since many of the drugs used to treat Bipolar Disorder have important drug-drug interactions with ART. At same time, the social worker and one of the nurses were at Susan's room along with her parents that recently arrived at the Hospital. As per Susan's request, they provided some education regarding HIV after she had disclosed her HIV status to her family members.

After a long admission, Susan was ready to be discharged. At that point in time, she required nurse support for daily activities including bathing and was taking over 30 pills per day. The team came to a decision that she could not live independently yet and needed support to increase adherence to ART. She would be transferred to Casey House. Casey House is one of the community partners from St. Michael's Hospital that provides community programs including home nursing care and outreach. Founded initially as a hospice that provided palliative care for those in need of end of life support. As HIV

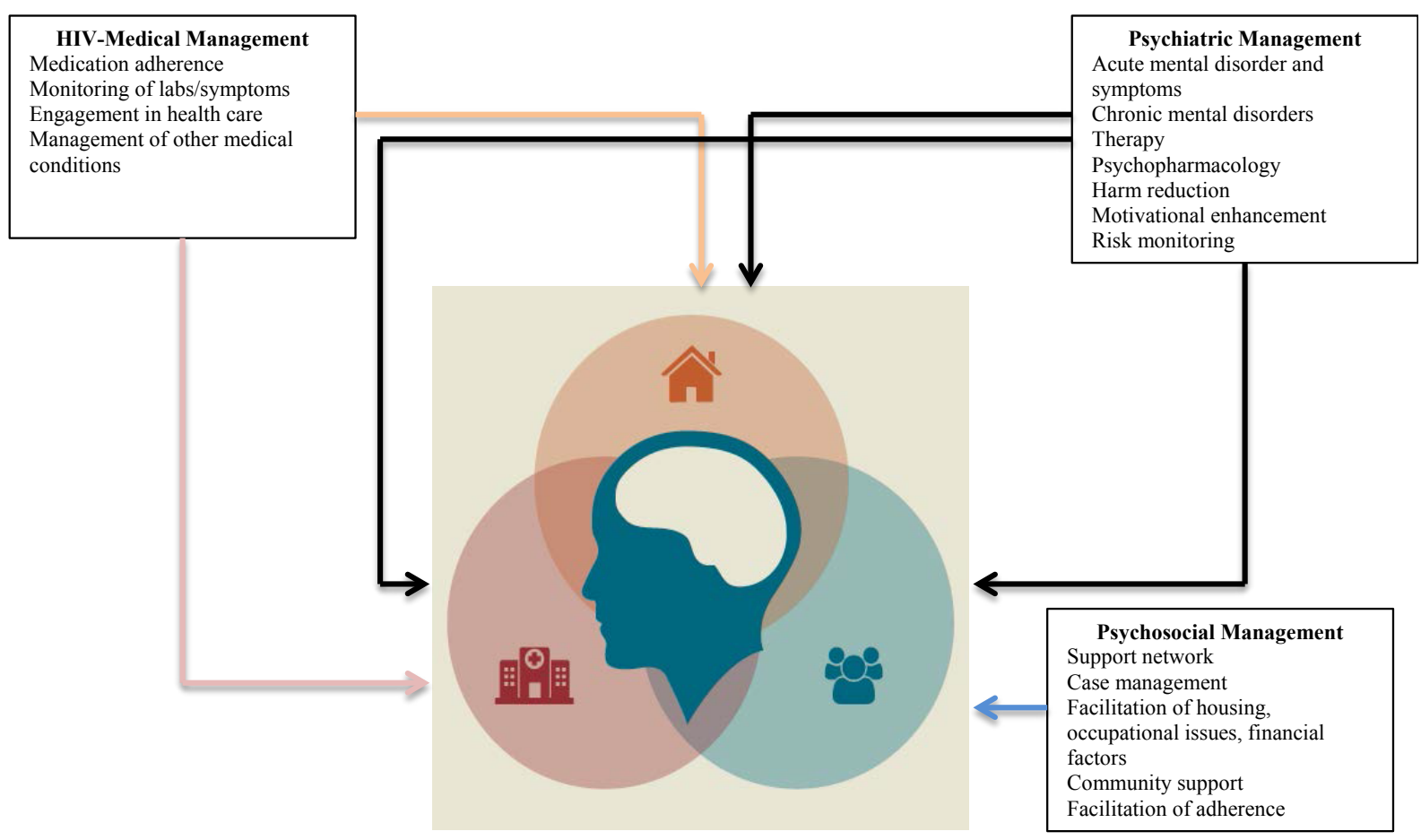

Figure 1: Model of Integrated HIV Care. 
evolved from a disease with high mortality to a chronic illness, Casey House has also changed the population served, currently provides care for patients with addiction and mental health, cognitive problems, and for those in need of community support. During her 6 months stay at Casey House the psychiatrist provided weekly follow-ups and helped the team to work with Susan, who at various occasions could be abusive and dismissive.

When Susan was about to leave Casey House, she was scheduled to receive follow-up care at HIV outpatient clinic and a family physician was arranged both part of St. Michael's Hospital. She still needed a great deal of support in the community and the psychiatrist advocated for her to be accepted by two other community partners from St. Michael's Hospital: McEwan Housing and Fife House. McEwan Housing is a supportive community support program for PHAs, who have mental health or addiction issues and are homeless or at risk of becoming so. It is the only housing program in Ontario dedicated to serving this highly vulnerable population. Fife House provides supportive housing and support services to PHAS. Through these two programs, Susan received housing, nursing support and intensive case management.

Fast forward - one year later - Susan has been stable, taking mood stabilizers and abstinent from drugs. She is adherent to the ARV treatment, CD4 has increased to 350 cells (from the initial 30) and viral load is undetectable. She still attends several medical appointments and is on the waiting list for liver transplant.

\section{Discussion}

Improvements in access to psychiatric services among patients certainly facilitated the engagement in HIV care and improved adherence to ART. Recently, the concept of HIV care cascade has emerged as a model that outlines the sequence of stages of HIV care that PHAs go through from initial diagnosis to achieving viral suppression [14]. Unfortunately, this sequence of steps is not seamless. Among people living with HIV, we know that not everyone is successfully diagnosed, linked to and engaged in care. The HIV continuum of care is one of the tools increasingly being used to determine how well the system is doing to engage and keep clients in care. The continuum is based on the successive steps that are needed for a person living with HIV to achieve an undetectable viral load, which is an optimal clinical endpoint. Strong engagement in care and undetectable viral load improves quality of life for the person living with HIV and reduces the risk of transmitting HIV to others [15]. Some people are lost in this continuum of care due to obstacles including difficulties to access care for mental health and addiction problems. In the integrated model of psychiatric care used at St. Michael's Hospital, HIV-infected patients with mental health problems have access to a system that is better equipped to respond to their unique psychosocial needs in order to improve the HIV care cascade. The multidisciplinary care approached used in this model reduce barriers to care for patients. When services are co-located or when linkages to external services are explicit, patients may be less likely to be lost to care. The ability to seek services in one space or being offered navigation between services that are not co-located may mean less planning for clients and may reduce the burden healthcare has on the lives of people with complex needs such being HIV and have addiction and mental health problems. The complexity of clinical needs among HIV-infected patients mandate treatment services that are comprehensive, integrated, continuous, and culturally responsive [16]. The global burden of mental health in HIV patients poses significant challenges to health care system. Management of mental illness and substance related disorders is emerging as a key element of risk reduction and amelioration in quality of life in PHAs. Ongoing research that looks at integrated care models for this population is necessary to provide recommendations on best practices for working with clients living with HIV.

\section{References}

1. Ellis $R$, Moore $D$, Childers $M$, Letendre $S$, J. Allen McCutchan, Wolfson $\mathrm{T}$, et al. (2002) Progression to neuropsychological impairment in human immunodeficiency virus infection predicted by elevated cerebrospinal fluid levels of human immudeficiency virus RNA Archives of Neurology 59:923-929

2. Bing E, Burnam M, Longshore D, Fleishman J, Sherbourne C, et al. (2001) Psychiatric disorders and drug use among himan immunodeficiency virusinfected in the United States Archives General Psychiatry 58:721-728

3. Carvalhal A, Baril JG, Crouzat F, De Wet J, Junod P, et al (2012) Recognizing cognitive and psychiatric changes in the post-highly active antiretroviral therapy era Can J Infect Dis Med Microbiol 23: 209-215

4. Gomez MF, Klein DA, Sand S, Marconi M, O'Dowd MA (1999) Delivering mental health care to HIV-positive individuals A comparison of two models Psychosomatics 40: 321-324

5. Ciesla JA, Roberts JE (2001) Meta-analysis of the relationship between HIV infection and risk for depressive disorders Am J Psychiatry 158: 725-730

6. Brennan A, Morley D, O'Leary AC, Bergin CJ, Horgan M (2015) Determinants of HIV outpatient service utilization: a systematic review AIDS Behav 19: 104-119

7. Stoff DM, Mitnick L, Kalichman S (2004) Research issues in the multiple diagnoses of HIVIAIDS, mental illness and substance abuse AIDS Care 16 Suppl 1: S1-5

8. Hussain M, Seitz D2 (2014) Integrated models of care for medical inpatients with psychiatric disorders: a systematic review Psychosomatics 55: 315-325

9. Frankel SA, Bourgeois JA2, Xiong G3, McCarron R4, Han J5, et al (2014) The medical-psychiatric coordinating physician-led model: team-based treatment for complex patients Psychosomatics 55: 333-342

10. Curran GM, Pyne J, Fortney JC, Gifford A, Asch SM, et al (2011) Development and implementation of collaborative care for depression in HIV clinics AIDS Care 23: 1626-1636

11. Ojikutu B, Holman J, Kunches L, Landers S, Perlmutter D, et al (2014) Interdisciplinary HIV care in a changing healthcare environment in the USA AIDS Care 26: 731-735

12. Kathol RG, Kunkel EJ, Weiner JS, McCarron RM, Worley LL, et al (2009) Psychiatrists for medically complex patients: bringing value at the physical health and mental health/substance-use disorder interface Psychosomatics 50: 93-107

13. Chan LG, Carvalhal A2 (2015) Journeying with HIV patients across the health care spectrum - an examination of a seamless model of HIV Psychiatry of a large urban general hospital Gen Hosp Psychiatry

14. Giordano TP (2015) The HIV treatment cascade--a new tool in HIV prevention JAMA Intern Med 175: 596-597

15. Skarbinski J, Rosenberg E, Paz-Bailey G, Hall H, Rose C, et al.( 2015) Human Immunodeficiency Virus Transmission at Each Step of the Care Continuum in the United States JAMA Internal Medicine 175:588-596

16. Durvasula R1, Miller TR (2014) Substance abuse treatment in persons with HIVIAIDS: challenges in managing triple diagnosis Behav Med 40: 43-52 